\title{
O SUJEITO MULTIFACETADO E A CONSTITUIÇÃO DA IDENTIDADE EM CIDADE LIVRE
}

\author{
THE MULTIFACETED SUBJECT AND IDENTITY'S \\ CONSTITUTION IN CIDADE LIVRE
}

\section{Ernani Müggel}

Recebido em: 06 de abril de 2017

Aprovado em: 22 de junho de 2017

Sistema de Avaliação: Double Blind Review

RPR | a. 14 | v. 2 | p. 89-98 | jul./dez. 2017

\section{RESUMO}

Cidade livre, de João Almino, reedifica a capital federal do Brasil, por meio da ficção. Para compor a trama, o narrador-personagem João vale-se de uma multiplicidade de fontes, como memórias pessoais, memórias e anotações de seu pai, relatos de pessoas e observações de blogueiros. O procedimento narrativo faz emergir uma constelação de personagens, de identidades que vão compondo o cenário da cidade livre, transformando-a em um território marcado por diferenças. Essas diferenças embasam e moldam a civilização que se estrutura no planalto central brasileiro, desafiando os sujeitos envolvidos a um constante exercício de alteração das identidades pessoais em favor de um novo projeto de sociedade. Analisar de que maneira se comporta esse sujeito multifacetado, assim definido por Stuart Hall diante da complexidade do mundo moderno em que a subjetividade se forja, e perceber como se constitui a identidade aberta e variada da nova cidade é o objetivo deste estudo.

Palavras-chave: Cidade livre. Identidade. Mito fundacional.

\section{ABSTRACT}

João Almino's Cidade Livre, reconstructs Brazilian's federal capital, by the use of fiction. To compose the plot, the narrator-character João applies a multiplicity of sources, like personal memories, memories and notes from his father, commentaries from people and commentaries from bloggers. The narrative process allows the emergence of a constellation of characters and identities that compose the landscape of cidade livre, turning it into a territory highlighted by differences. These differences found and mold the civilization structured in Brazilian's central plateau, leading the involved subjects into a constant exercise of personal identity variance in favor of a new society project. Analyzing the way this multifaceted subject behaves, as defined by Stuart Hall in the presence of modern world's complexities where subjectivity is forged, and realize how the open and varied identity of the new city is constituted reveals to be the purpose of this study.

Keywords: Cidade livre. Identity. Foundational myth.

\section{INTRODUÇÃO}

Cidade Livre, nome que dá título ao quinto romance de João Almino (antecederam a este, Ideias para onde passar o fim do mundo (1987), Samba-enredo (1994), As cinco estações do amor (2001) e $O$ livro das emoções (2008)), é a primeira designação do território que acolheu trabalhadores oriundos de várias regiões do Brasil para colaborar na construção de Brasília - os candangos, e que posteriormente recebe o nome de Núcleo Bandeirante.

\footnotetext{
${ }^{1}$ Doutor em Literatura Brasileira, Portuguesa e Luso-africana pela Universidade Federal do Rio Grande do Sul (Porto Alegre/Brasil). Professor na Universidade Feevale (Novo Hamburgo/Brasil). E-mail: ermugge@ feevale.br.
} 
A escolha do título da obra justifica-se porque realça o espaço que acolhe personagens significativas da trama, o território chamado Cidade Livre. É nela que essas personagens, de origens e de histórias diferentes, se estabelecem e, por meio de suas posições, evidenciadas no contato uns com os outros, expõem e acentuam suas individualidades, aclarando traços de suas identidades.

A trama é estruturada em uma introdução e sete capítulos, estes já enunciados no subtítulo daquela - "Sete noites e um enterro", em referência ao tempo em que o narrador passou com seu pai adotivo, então com 82 anos, moribundo em uma cela de prisão. Em um pequeno quarto, o filho, JA ou João, estimula Moacyr Ribeiro a relembrar momentos do processo de construção de Brasília. Ambos, ao lado de tia Francisca e tia Matilde, fazem parte do grupo pioneiro da Cidade Livre, sendo, assim, testemunhas e agentes do crescimento tanto da comunidade quanto da edificação de Brasília, presenciando inúmeros fatos, transcritos sob o filtro da memória na narrativa.

Essas personagens, em fevereiro de 1957, poucos meses após sua chegada, estão entre as quatrocentas pessoas que presenciam a inauguração da cidade (ALMINO, 2010, p. 41), que atrai cada vez mais gente, do Brasil e do exterior, para se fixar no lugar. A proprietária do Hotel Santos Dumont, ex-refugiada polonesa, "a então jovem e atraente condessa Tarnowska" (ALMINO, 2010, p. 41), é "apenas uma entre os muitos estrangeiros - cujos nomes esqueci, nomes árabes, judeus, portugueses, espanhóis, italianos, alemães, belgas, franceses, russos, gregos e poloneses" que aí se estabeleceram (ALMINO, 2010, p. 42). Entres os brasileiros que se instalam no lugar, há "predomínio de mineiros e nordestinos" (ALMINO, 2010, p. 43).

A "invasão" é descrita desta maneira pelo narrador:

[...] candangos, muitos candangos, sobretudo homens que chegavam sem suas mulheres com a esperança de serem fichados nas empresas construtoras, trazendo malas de madeira ou trouxas, um caneco de alumínio e uma faca presos no cinturão, como era o hábito de Valdivino (ALMINO, 2010, p. 21).

Como a infraestrutura é precária diante de tamanha imigração, surgem várias comunidades: Morros do Urubu e Querosene, Vila Esperança, Vila Tenório, IAPI, Divineia, Vicentina e Sarah Kubitschek (ALMINO, 2010, p. 43).

À medida que o lugar cresce, recebe inúmeras visitas de autoridades, de diversas áreas, como os escritores Elisabeth Bishop e Aldous Huxley, o primeiro- ministro de Cuba, Fidel Castro Ruz, o escritor e ministro da Cultura da França, André Malraux, o crítico de arte José Gudiol, entre outros, cuja presença, mesmo que passageira, tem reflexos na constituição da identidade local, pelo fato de eles se manifestarem sobre a construção de Brasília; muitos dessem depoimentos são registrados por Moacyr Ribeiro em seu caderno Avante.

A construção da capital do Brasil no Planalto Central, portanto, resulta de "deslocamentos", o que implica o distanciamento das personagens de sua origem e o contato com o novo, com o diferente. $\mathrm{O}$ duplo movimento - de afastamento das raízes e de aproximação com o distinto - significa a inserção do Eu em nova ordem, em que a necessidade de identificação com o diverso é inexorável. Na medida em que esses sujeitos de distintas origens e, portanto, culturas, interagem, evidencia-se a concepção de um sujeito multifacetado, sem uma "ancoragem" no mundo social, processo derivado das "transformações associadas à modernidade" que "libertaram o indivíduo de seus apoios estáveis nas tradições e nas estruturas" (HALL, 2000, p. 25).

Portanto, a origem de Brasília, reedificada ficcionalmente por João Almino em Cidade livre, sustenta-se sobre o movimento migratório, na medida em que é construída sobre um território desabitado, para o qual convergem pessoas oriundas de todo o Brasil em busca de trabalho e 
prosperidade e necessitando adaptar-se a um novo contexto. Assim sendo, o romance é campo fértil para a análise de como se configuram e se comportam as identidades fragmentadas.

A análise da constelação de personagens, que se entrecruzam em movimentos de identificação e recusa, pode ser construída a partir de Moacyr Ribeiro, que se constitui, assim, em ponto de partida para a percepção de seus interlocutores: Bernardo Sayão, João, Tia Francisca, Tia Matilde, Paulão, Valdivino e Íris Quelemén.

\section{CONSTELAÇÃO: IDENTIFICAÇÕES E NEGAÇÕES EM CIDADE LIVRE}

O processo de construção de Brasília dá origem a ondas de migração, cujos protagonistas buscam novas oportunidades de vida. O narrador, participante ativo dessa epopeia, ao se propor a recuperá-la, tem a missão de reconfigurar a si mesmo e a esses protagonistas, já homogeneizados na memória, para restaurar-lhes suas antigas identidades. Para tanto, retorna a sua infância, quando, aos seis anos, é levado pelo pai adotivo (sua família morrera em um desastre), Moacyr Ribeiro, e pela tia, Francisca, de Ceres, onde residem, para a Cidade Livre.

Moacyr, caso se use o critério temporalidade, é a primeira das personagens a vivenciar o afastamento de uma base sólida e segura na medida em que se muda de Belo Horizonte para o Rio de Janeiro, do Rio de Janeiro para Ceres e, de lá, finalmente, para o Planalto Central. Formado em Medicina, em Belo Horizonte, escolhe a Psiquiatria como especialização, o que o leva a estagiar no Rio de Janeiro, visto que, à época, "eram poucos os locais para formação psiquiátrica" (ALMINO, 2010, p. 32). Um fator da vida pessoal - o malogrado casamento, que o leva ao alcoolismo e à amargura - faz com que ambicione "se esconder nos confins do Brasil" para cuidar de João, filho de um "primo remediado", após o acidente da família deste. A tia de João, Francisca, que herdara a fazenda da irmã e do cunhado em Ceres (Goiás) e ficara com a guarda do menino, "depois de refletir muito" (ALMINO, 2010, p. 33), aceita a ideia de o médico ir morar no município goiano, impondo uma condição a ele, ateu declarado: que o sobrinho seja educado na religião católica, no que é atendida. Moacyr, assim, ultrapassa fronteiras novamente, iniciativa que o coloca em um segundo "entre-lugar", na medida em que, se considerado o espaço geopolítico e sua cultura própria, no Rio de Janeiro ele já não era mais puramente mineiro, sendo, também, carioca, e posteriormente passa a ser goiano. Portanto, Moacyr está no interstício de diferenças culturais, ao situar-se em regiões distintas entre si, apesar de estarem integradas a um mesmo país. Acresce-se que a personagem ainda se desloca para o Planalto Central, onde será erguida a nova capital do Brasil.

O romance Cidade livre, assim, promove a aparição de um sujeito híbrido, reconfigurado pelo movimento migratório, que evita recuperar, pela memória, vivências do passado, o que se justifica, em parte, pelo objetivo do narrador, que se restringe a contar apenas a história de Brasília. Entretanto, o leitor pode perceber que Moacyr é uma personalidade inquieta e aventureira, que busca, incessantemente, romper fronteiras. Essas características transparecem no ensinamento que ele dá ao filho adotivo, que revela: "Tivera sorte que papai quisera vir morar conosco, cuidar de mim e tivesse incutido em mim desde cedo a ideia de que eu deveria abrir os olhos para a vastidão de um mundo muito maior do que Ceres" (ALMINO, 2010, p. 34).

A mudança de Moacyr para Ceres, sob essa ótica, pode ser vista, pelo leitor, como contradição, inferência que o próprio narrador desfaz, ao afirmar que o pai adotivo "tinha o desejo de se esconder

\footnotetext{
2 Para Homi K. Bhabha (2010, p. 20), “entre-lugar" é um local intersticial, que fornece "terreno para a elaboração de estratégias de subjetivação - singular ou coletiva - que dão início a novos signos de identidade e postos inovadores de colaboração e contestação, no ato de definir a própria ideia de sociedade".
} 
nos confins do Brasil" (ALMINO, 2010, p. 32). Note-se que o termo "esconderijo" remete a algo passageiro, transitório, termo que converge para a personalidade do médico, e a leitura confirma-se quando, pouco tempo depois da mudança, Moacyr se convence de que ajudar a construir Brasília é uma “oportunidade imperdível”. À primeira vista, a decisão novamente parece um contrassenso diante de seu perfil, pois o lugar escolhido para morar é distante e desabitado: "Viemos em vários dias no jipe Willys azul de papai cortando às vezes terrenos sem estrada, primeiro em direção de Cabeceira Grande, onde o Rio Preto serve de divisor entre o Distrito Federal e Minas Gerais, e por ali pegamos a estrada de Unaí" (ALMINO, 2010, p. 34-35) A contradição, entretanto, se desfaz diante da magnitude do projeto em início de execução, que, em breve espaço de tempo, ergueria do nada "a primeira das capitais da nova civilização" (ALMINO, 2010, p. 64), como viria a afirmar, em 1959, André Malraux, conforme registrado nos cadernos de Moacyr.

Em solo da capital federal, o espírito aventureiro de Moacyr se confirma, mais uma vez, quando ele se nega a trabalhar como médico e se oferece como redator a Bernardo Sayão, vice-governador de Goiás e um dos diretores da NOVACAP, a Companhia Urbanizadora da Nova Capital do Brasil:

Papai lhe lembrou que engenheiro não era, mas gostaria de acompanhar as obras da Goiânia-Brasília, se dedicaria a observar e anotar tudo, para que no dia da inauguração de Brasília fosse publicado um relatório minucioso daquela epopeia sob a ótica de quem a vivera dia a dia, um "Livro de Ouro de Brasília", do início da construção até a inauguração (ALMINO, 2010, p. 35-36).

O desejo de Moacyr de ser redator da história dos acontecimentos que envolvem a construção de Brasília evidencia sua disposição de ter uma vida itinerante, em detrimento da estabilidade que a medicina poderia lhe oferecer.

O aceite da proposta por parte de Sayão permite ao médico desenvolver outras atividades além da de redator: o fato de estar entre os primeiros moradores de Cidade Livre lhe proporciona a possibilidade de comercializar os lotes: "Moacyr, como foi um dos primeiros a chegar à Cidade Livre, além da atividade de "historiador" e "jornalista", entrou em um ramo lucrativo: comerciante de comodato." (ALMINO, 2010, p. 43) As múltiplas habilidades do pai fazem com que o filho criasse uma imagem positiva dele: "gênio das letras e dos negócios", "que sabia falar com uns e com outros, sem se comprometer e tirando bom proveito das circunstâncias" (ALMINO, 2010, p. 43).

Tomada sob perspectiva da identidade, a opção de Moacyr em atuar em diversas frentes de trabalho, insere-o em contextos distintos: no sociocultural e político, por testemunhar eventos importantes no processo de construção da capital federal, e no econômico, quando se envolve em operações comerciais. Além disso, ele ainda está imerso em um ambiente familiar pouco usual, constituído por ele, tia Francisca, tia Matilde e João, o filho adotivo. O contato de Moacyr com os sujeitos que se enquadram nestes três círculos - também, como ele, vindos de fora - exigem permanente esforço para "cambiar" sua identidade, confirmando o posicionamento de Hall de que "o sujeito assume identidades diferentes em diferentes momentos, identidades que não são unificadas ao redor de um "eu" coerente" (HALL, 2011, p. 13).

A pluralidade de identidades de Moacyr pode ser percebida ao longo da narrativa, em movimentos de recusa e de identificação, tanto com espaços, - mas sem que se possa vislumbrar uma ancoragem segura e estável -, quanto com outras personagens, estas igualmente desenraizadas e envoltas por múltiplas facetas. O sonho de registrar a construção de Brasília aproxima o mineiro de Bernardo Sayão, o engenheiro que não gostava de "palavreado" (ALMINO, 2010, p. 36), por quem nutria sentimento de gratidão, pois fora responsável pela sua ida à Cidade Livre. É a ele que recorre quando percebe que a ideia de acompanhar visitantes não se concretiza, oferecendo-se para registrar o processo de construção 
da rodovia Belém-Brasília, "[...] e não apenas porque precisava de um retiro espiritual. Sentia saudades do bom humor de Sayão, de sua atividade permanente [...]" (ALMINO, 2010, p. 146). A passagem assinalada evidencia o deslocamento de Moacyr, tanto do espaço quanto das relações com pessoas próximas, como tia Francisca, com quem se desentendera, e Lucrécia, a amante que sumira de sua vida. Entretanto, as incursões à floresta foram poucas e breves. Conforme o narrador, "se no Planalto Central ele se sentia abandonado pelos largos horizontes, aqui ele se considerava esmagado por sua ausência" (ALMINO, 2010, p. 153). Além disso, também "não podia se afastar de seus negócios por muito tempo e não queria perder a inauguração do Palácio da Alvorada, que reuniria centenas de visitantes ilustres" (ALMINO, 2010, p. 154).

A volta e a reconciliação com tia Francisca traduzem a valoração da segurança, endossada pelo núcleo familiar. O narrador percebe mudança no pai: "Quando chegou de sua viagem à selva, notei que algo de novo acontecera, acho que a distância serve para separar de vez quem não está destinado a ficar junto e noutros casos reaproxima quem não consegue se separar" (ALMINO, 2010, p. 154). Neste caso em particular, Moacyr percebe a importância de tia Francisca para sua vida, na medida em que restabelecer o vínculo com ela também significa reconstituir códigos culturais - de família - adquiridos a partir da vivência de ambos. Isso significa dizer que, em meio à adversidade do meio, que lhe oferece múltiplas novas vivências, sobressaem-se laços já estabelecidos, que levam os dois a contrair matrimônio, apesar das diferenças entre eles.

Tia Francisca, aliás, tem papel fundamental na vida de Moacyr, na medida em que, por meio de seu aceite em acomodá-lo na fazenda de Ceres, traça, também, o destino, não só dele, mas de todo o grupo "familiar" que irá se constituir a partir da mudança dele para o município goiano. Ativa, caprichosa, religiosa, recatada, cuida da casa e de seus mais próximos, em especial do sobrinho, João, e de Moacyr, tornando-se, assim, porto seguro de ambos. Preocupa-se com a aparência de Moacyr a ponto de sugerir que procure um alfaiate: "Ela opinava sobre tudo à nossa volta, especialmente sobre os gostos de papai, Por que você não faz um terno de linho, agora tem um bom alfaiate aqui na Cidade Livre, você precisa de se mostrar mais elegante, homem" (ALMINO, 2010, p. 46).

Tia Matilde, por sua vez, em nada se compara a ela. As diferenças entre ambas, assinaladas pelo narrador, podem ser percebidas nas vestes e nos gostos musicais. João observa, no varal, "as calcinhas coloridas de tia Matilde e as brancas de tia Francisca; os corpetes grandes de tia Matilde e os menores, de tia Francisca; os vestidos de mangas de tia Francisca, os de alça de tia Matilde; as anáguas de tia Francisca e os shorts de tia Matilde" (ALMINO, 2010, p. 46, 47). Em relação à preferência musical, enquanto tia Francisca prefere canções românticas, com doses de melancolia, canções de Nelson Gonçalves, de Dolores Duran, de Ângela Maria e Maysa, tia Matilde tem gosto mais variado, alternando Frank Sinatra, Nat King Cole, João Gilberto e Celly Campelo. As duas mulheres agem de maneira distinta sobre as personagens masculinas da casa. João estabelece relação mais próxima com tia Francisca, por quem nutre amor platônico a ponto de desenvolver sentimento de disputa com Valdivino, enquanto é mais distante de tia Matilde, o que faz com que não tenha a liberdade de brincar com ela. Entretanto, é Matilde que o seduz, ainda menino, e com quem ele estabelece um vínculo ideológico quando adulto.

Se tia Francisca simboliza o acolhimento, a retidão, o anacrônico, a moderação, a virtude, Tia Matilde singulariza-se pelo despreendimento, pela ousadia, pela coragem, pela extroversão, pela sensualidade, pelo pecado. O narrador, ao comparar as duas, afirma que tia Francisca, ao contrário de tia Matilde, "nunca levantava a voz. Tinha uma polidez e educação vindas do berço, algo que lhe era natural, que parecia não ter sido aprendido, que não provinha de regras mas apenas de temperamento" (ALMINO, 2010, p. 150). 
Matilde, ao simpatizar, a partir de determinado momento, pela ideia da revolução, institui e personifica o contraponto, não só com tia Francisca e com Moacyr, mas com os próprios rumos que a sociedade está tomando. "Estamos numa canoa furada" (ALMINO, 2010, p. 64), reconhece. Entretanto, no entendimento do narrador adulto, apesar de suas atitudes e posições políticas, ela não é superficial, desregrada ou alguém destituído de princípios rígidos, (ALMINO, 2010, p. 151), qualidades que justificam a identificação e o apreço que ele tem por ela.

As características de cada personagem e visões de mundo acabam por aproximar João e tia Matilde, por um lado, e Moacyr e tia Francisca, por outro, constituindo duas esferas distintas. O estopim do desentendimento entre o narrador, seu pai e tia Francisca centra-se em um artigo escrito por João, cujo teor não está explícito, mas passível de dedução por parte do leitor, que sabe do envolvimento do autor do texto com o movimento revolucionário.

A saída de João da casa do pai aproxima-o em definitivo de tia Matilde, que o acolhe e apoia: "Ela simpatizava com minhas ideias, comentava meus artigos, sonhava com o socialismo e era crítica dos militares, como eu" (ALMINO, 2010, p. 212).

Outra personagem expressiva no romance de João Almino, responsável direto pelo enriquecimento de Moacyr, é Paulão. Eles se conhecem em um bar, apresentados pela proprietária, Carmem. A Paulão interessa a aproximação com Moacyr, pois sabe que este é "bem relacionado com os círculos do presidente e da Novacap" (ALMINO, 2010, p. 123). Seu único propósito é se aproveitar do contexto para enriquecer:

Aqui neste Planalto Central corre muito dinheiro, doutor Moacyr, é só ter uma graninha para investir e aí ela se multiplica sozinha, não faz um ano que cheguei da Bahia e não me queixo; olha, doutor Moacyr, tem muito dinheiro circulando neste Planalto Central, e a gente não pode deixar de abocanhar a parte que nos cabe, não é mesmo, só o dinheiro que o governo traz pra cá. (ALMINO, 2010, p.123-124).

A intenção de Paulão é de se especializar como gato, "empreiteiro terceirizado pelas firmas de construção" (ALMINO, 2010, p. 124), o que o isenta de assinar carteira dos empregados. O baiano propõe sociedade a Moacyr: "o senhor só arranja os contatos, consegue que a gente preste os serviços, e eu cuido do resto; o senhor tendo algum dinheiro, a gente pode também aumentar a compra de areia, confie em mim, vamos ter grandes lucros" (ALMINO, 2010, p. 129, 130). Com o aceite, o prenúncio do proponente se realiza, e os sócios enriquecem, graças a negócios ilícitos, articulados por Paulão, que tem "habilidade especial de conseguir três ou quatro notas de fornecimento de caminhão de areia, brita ou cimento com apenas uma viagem" (ALMINO, 2010, p. 179, 180). Há outros procedimentos, como "colocar candangos de outras obras na lista, pagar e depois pegar a maior parte do dinheiro de volta", colocar o caminhão em cima de vigas e deixar rodar toda uma noite para aumentar a quilometragem, quando o pagamento é feito pela distância percorrida. O enriquecimento vem acompanhado por prestígio, não só na Cidade Livre, mas em toda Brasília.

Entretanto, a fortuna de Moacyr se esvai assim como a liberdade: acaba na prisão, "por não terem conseguido perdoar a um construtor inventivo a falta de pagamento de impostos e a desobediência ao plano dos arquitetos" (ALMINO, 2010, p. 228).

Paulão, além da riqueza, também apresenta a Moacyr a misteriosa e controvertida prostituta Lucrécia, que já trabalhara para ele na Bahia. Na cama com o recém-conhecido, ela revela, entre gritos descontrolados: "Na comunidade que eu vou criar, o novo mandamento vai ser: faça amor desde que não prejudique ninguém, [...], em vez de missas, devíamos fazer festas purificadoras, como um culto à fertilidade, você não acha, como no povo banto" (ALMINO, 2010, p. 133). Surge, desse desejo, tempos depois, após sumir da vida de Moacyr, o Jardim da Salvação, local em que, conforme a profetiza Íris 
Quelemém, "os desesperados do mundo vão encontrar o seu caminho" (ALMINO, 2010, p. 221). O Jardim (segundo Valdivino) é o lugar a que recorrem, principalmente, ex-drogados, assassinos arrependidos, ex-prostitutas que buscam uma vida nova. Moacyr assiste o sermão proferido pela profetiza aos seus seguidores e,

[...] mesmo sem acreditar, registrou suas palavras e concluiu, em pensamentos que pareciam vivos e cristalinos, que o Jardim da Salvação era uma porta de entrada para a contribuição ao mundo que podiam fazer os extremistas, os fanáticos, os loucos, os lunáticos, os deprimidos, os desesperados e os incompreendidos. Ali eles adquiriam relevância. Ali eles descobriam sua missão (ALMINO, 2010, p. 222).

Ao reconhecer a importância do Jardim, Moacyr também identifica o contexto que o envolve, marcado pela proliferação de crenças e seitas e, paralelamente, seu lugar nesse espaço: "Brasília era o refúgio do desespero; do seu próprio desespero, que, recalcado e esquecido desde que deixara o Rio de Janeiro para morar em Ceres com tia Francisca, parecia agora ressurgir" (ALMINO, 2010, p. 222).

O reconhecimento do contexto e as palavras de Íris, que julga ressoarem nele por causa do líquido que ingerira ao adentrar o primeiro dos três portais do Jardim, tornam Moacyr vulnerável a ponto de oscilar entre o posicionamento de Íris, singularizado pela defesa de que o destino das pessoas está traçado, e pela ideia defendida pela irmã Matilde, que se sustenta sobre a liberdade e do controle do futuro. Esse embate expõe a desagregação da personagem, que hesita diante dos discursos que o perturbam, sendo, seduzido, momentaneamente, pelo poder da retórica de Íris, que o qualifica como uma espécie de fantoche de feições animalescas: "Você é como a formiga que caminha em cima de um cavalo de forças invisíveis, forças do fundo da mente, forças da alma, formiga que inventa histórias de que está decidindo sobre o futuro"; "você não está conduzindo o jumento, é só um carrapato no couro do jumento" (ALMINO, 2010, p. 224). Conforme o narrador, Moacyr acredita, por um momento, que ela tinha razão, e que, como a consciência não pode barrar os desejos, o sujeito é isento de culpa.

Valdivino é outra personagem que merece ser destacada na análise das identidades que compõem a Cidade Livre pela expressividade que assume ao longo da narrativa. O narrador, ao vê-lo sentado com seu pai e Roberto, descreve-o dessa maneira:

O terceiro, de uma simplicidade tosca, com chapéu grande demais para sua cabeça pequena, é conversador, parece inteligente e é o único com esporas nas botas, tendo chegado montado num burro, mas, se atrai minha atenção, é por sua fragilidade. Quando tira as mãos do bolso, gesticula sem parar, balança-se para frente e para trás sobre suas pernas de cambito e dá a impressão de que sairá voando se soprado pelo vento" (ALMINO, 2010, p. 25-26).

A fragilidade que o narrador percebe no aspecto físico de Valdivino estende-se, também, à esfera emocional. Sonhador, ingênuo, crédulo, envolve-se, frequentemente, em situações das quais sai fragilizado. Natural da Bahia, Valdivino tem como missão de vida erguer igrejas. Conquista a simpatia e a amizade de tia Francisca, para quem ele é um "prodígio" por sua capacidade de aprendizagem, qualidade que não é compartilhada por Moacyr e tia Francisca, para quem ele tem "apenas talento para falar sem parar" e para "conhecer plantas e bichos, nada mais" (ALMINO, 2010, p. 96).

A amizade de Valdivino e tia Francisca provoca ciúmes em João, a ponto de este desejar a morte do desafeto, sentimento que lhe rende, posteriormente, com a morte do baiano, sentimento de culpa. Os ciúmes têm origem na desconfiança de João de que tia Francisca gostava de Valdivino. Este, entretanto, nutre um sentimento de paixão (ou seria amor?) por outra mulher, "em torno de quem sempre fazia mistério" (ALMINO, 2010, p. 67). Apesar de a identidade dessa mulher ser esclarecida nos últimos capítulos - trata-se da prostituta/profetisa Lucrécia/Íris Quelemén, outro mistério não é resolvido: seria 
ela mãe ou amante de Valdivino? O leitor precisa tirar suas próprias conclusões, visto que isso não é resolvido na obra.

Assim como a origem de Valdivino não é explicitada, também sua morte fica em suspenso: Fora assassinado pelo coronel nordestino, com quem contraíra dívida para migrar para o Centro-Oeste? Ou pelo desafeto Aristóteles, o "policial da GEB" com quem dividia o dormitório? Ou por Moacyr, durante uma briga por causa de Lucrécia? Ou nenhum destes?

Tal como o crime não é esclarecido - até porque não há investigação - o pós-morte de Valdivino também adentra o domínio do mistério, a partir da especulação, levantada pela profetisa, de que houvera uma ressurreição:

Quando papai voltou ao Jardim da Salvação dois dias depois, Íris lhe disse, Ele é um santo, para explicar por que o corpo de Valdivino não apodrecia. Nunca vai apodrecer, vaticinou, e mais tarde espalhou que Valdivino ressuscitara, estava vivo, embora papai nem ninguém lá em casa nunca mais o tivesse visto (ALMINO, 2010, p. 30).

A ressurreição de Valdivino torna-o mito na cidade que ele ajudou a erguer, de origem igualmente mítica, pois a escolha do local da fundação da cidade centra-se na profecia de dom Bosco.

Portanto, as diferenças são marcas das personagens da Cidade Livre. Na medida em que essas personagens - diferenciadas - estruturam a nova civilização, elas lhe transferem suas características. De acordo com essa perspectiva, Brasília pode ser vista como uma cidade de origem múltipla e, portanto, de identidade igualmente múltipla e aberta.

Além disso, é preciso destacar que Cidade livre, ao se propor a narrar as origens de uma civilização, assume a tarefa de engendrar o mito fundacional da identidade brasileira, erguido a partir de uma memória frágil, pois, conforme o narrador, o passado "era apenas uma lembrança possível, um conjunto de migalhas" (ALMINO, 2010, p. 233). Igualmente ele reconhece sua incapacidade de ser coerente na constituição das personagens: "Ninguém conhece ninguém na sua totalidade, a gente vai formando em nossa cabeça o retrato impressionista dos outros com elementos que a gente vai juntando aqui e ali, mas o quadro pode mudar quando enxergamos outro ângulo, pois é pintado por nosso próprio pensamento" (ALMINO, 2010, p. 230). Assim, o mito é forjado pela subjetividade do olhar do narrador, que reconhece, inclusive, a impossibilidade de reconhecer a si mesmo: "Olhando-me no espelho do passado, onde às vezes não me reconheço, nada invento, apenas escrevo o relato do que vivi, que fica como um testemunho, entre muitos que podem existir, para compor o quadro de uma época" (ALMINO, 2010, p. 237).

\section{CONSIDERAÇÕES FINAIS}

A análise, mesmo que sucinta, de personagens significativas do romance Cidade livre revela que, apesar de estarem enleadas pelo mesmo objetivo, o de construir a capital federal do Brasil, elas compõem um quadro que se caracteriza pela diversidade, em função das distintas origens e experiências de vida. Assim sendo, o cenário se apresenta como uma "constelação", pois composta por um conjunto de sujeitos, cuja dinamicidade consiste na busca ora por aproximação, ora por afastamento do outro, podendo este, tanto estar consubstanciado em uma pessoa física quanto em um conceito, uma ideia, um propósito, articulado com o Zeitgeist ${ }^{3}$ reinante.

Esse movimento, independente de sua característica, pode ser compreendido a partir da inexistência de um núcleo social já constituído - com o qual as personagens poderiam se identificar ou

\footnotetext{
${ }^{3}$ Termo aqui utilizado como atmosfera ideológica, moral e cultural.
} 
recusar - e do estranhamento que domina a cada uma delas, sensação gerada pelo fato de serem migrantes ou "estrangeiros".

A ausência de núcleos de interação no território sobre o qual se ergue Brasília, os quais poderiam servir de apoio aos migrantes, reforça o processo de fragmentação da identidade dos sujeitos, tal qual preconiza Stuart Hall, o que justifica, em parte, os movimentos que eles realizam ao longo da narrativa em busca de algo que lhes assegure um mínimo de estabilidade. A imagem que se constrói, assim, é de personagens flutuantes, suspensos, livres de referenciais canonizados, mas ativos na busca e na construção de novos paradigmas e enlaces. Essa condição - de desenraizados operantes - torna nebulosa a "constelação", dificultando, ao leitor, a identificação das personagens. Quem é, afinal, Moacyr, Bernardo Sayão, João, tia Francisca, tia Matilde, Paulão, Valdivino e Íris Quelemén?

Moacyr é médico, com especialização em psiquiatria, mas vai para o planalto central para exercer a função de engenheiro. Na chegada, constatado o equívoco na sua inscrição, se oferece a Bernardo Sayão para redigir a história da construção de Brasília, atividade que realiza apenas parcialmente, pois tem dificuldades de se aproximar da maioria das personalidades que visitam Brasília para registrar as impressões deles sobre o processo de construção da capital. Assim, também não se torna escritor, e suas anotações acabam abandonadas em caixas. O êxito no ramo do comércio é sufocado por erros e pela consequente prisão. Assim como a vida profissional, a vida pessoal também é marcada por contradições: a generosidade revelada pela iniciativa em adotar João, um parente apenas distante, dá lugar à exploração de pessoas desafortunadas a quem vende lotes irregulares de terras.

O protagonismo de Bernardo Sayão em terras do Centro-Oeste, como político e engenheiro, confunde Moacyr, que o qualifica como "o mais ousado dos goianos", equívoco logo corrigido pelo interlocutor: "Não sou goiano, doutor Moacyr, sou carioca da Tijuca" (ALMINO, 2010, p. 40).

João (ou JA, como assina na introdução) caracteriza-se pela mudança, pela oscilação de pontos de vista e pela incerteza, traços que se desenvolvem nele pelas circunstâncias em que vive. Dessa forma, a incapacidade de apreender a complexidade do ser humano leva-o a compor uma imagem contraditória do pai ao longo da vida, sem que chegue a uma conclusão sobre o modo de avaliá-lo, até mesmo em face da morte dele. Quando criança, impressionado com as qualidades e atributos das mulheres da casa, ora se identifica mais com tia Francisca ora com tia Matilde. Transforma-se, com o passar do tempo, em homem "calado e sisudo" (ALMINO, 2010, p. 210), que reconhece a dualidade do mundo ao perceber que está dividido entre as atividades práticas do cotidiano e a missão de tecer sua história, ainda incompleta:

Minha vida se passa em dois planos distintos: levo os meninos para a escola, chamo o encanador para consertar a torneira da pia, limpo a piscina e, ao mesmo tempo, é como se estivesse vivendo num mundo outro, de história única e eterna, que ainda não conheço completa e que eu mesmo vou procurando compor (ALMINO, 2010, p. 22).

Tia Francisca, tia Matilde e Paulão são personagens que se mostram menos difusas ao longo da narrativa, ao contrário de Valdivino e Íris Quelemén. O primeiro, na medida em que gera uma série de dúvidas sobre ele, fomenta o mistério: Que motivos o levaram ao Planalto Central? Ele é filho ou amante de Lucrécia? Ou ambos? Que sentimento ele nutre por tia Francisca? Quem o matou? Ele, de fato, ressuscitou e virou santo? Some-se a isso outras curiosidades: no Jardim da Salvação ele é conhecido pelo codinome Abel, particularidade que estabelece correlação com a personagem bíblica de mesmo nome, assassinado pelo irmão, Caim, por ciúmes. Constitui-se ele, Valdivino, não pastor de ovelhas, como a personagem do Antigo Testamento, mas construtor de igrejas, o primeiro mártir da nova 
civilização que se ergueu, atestando, assim, a insignificância desse tipo de profissional? Essa inferência é abonada pela data da morte, 22 de abril, um dia após a inauguração de Brasília.

A prostituta Lucrécia, amante de Moacyr e de Paulão, e Íris Quelemén, a sacerdotisa do Jardim da Salvação, habitam o mesmo corpo. Não há uma clara separação entre ambas: a segunda vive na primeira, o que o leitor pode constatar logo que ela conhece Moacyr. Na oportunidade, ela afirma, entre outras coisas, que Brasília só seria construída se os espíritos do passado colaborassem e que D. Pedro II seria anfitrião das demais almas (ALMINO, 2010, p. 132, 133). Já como Íris Quelemén, afirma que Valdivino não morreu, mas sobrevive em Karaí (ALMINO, 2010, p. 28). É considerada louca por Moacyr, tem fama de vadia na Cidade Livre e é vista por Valdivino como uma pessoa de temperamento difícil, que tem "umas visões e revelações" e vê fantasmas (ALMINO, 2010, p. 204). Quem é ela senão essa conjunção de identidades, que se revelam de uma maneira para alguns e, de outra maneira, a outros?

Enfim, Cidade Livre se notabiliza por apresentar essa constelação de personagens indefinidas, dúbias, misteriosas, obscuras, de múltiplas identidades, que, por consequência, fundam, também, uma cidade cuja identidade se caracteriza como aberta e variada. Na medida em que o texto reedifica, ficcionalmente, o começo dessa civilização, assinalando traços e feitos de seus protagonistas, ele se constitui em mito fundador para a identidade brasileira. Moacyr assume papel de protagonista, não só por atrair, ao redor de si, as demais personagens, mas, em especial, por registrar fatos e frases memoráveis da época da construção de Brasília, engendrando uma narrativa de cunho fundacional. Entretanto, se o Caderno Avante se notabiliza por carregar o imemorável - que acaba enterrado - seu dono carrega no próprio nome a dor: Moacyr, de origem tupi, significa "dolorido, magoado", "o que vem da dor" ou "o que faz doer, o que magoa"4 . O nome remete também ao filho de Martim e de Iracema, também ele filho do sofrimento e de um processo de ocupação e de povoamento gestado sobre a espoliação e a subjugação dos mais fracos pelos mais fortes. Estabelecido o paralelo, a identidade de Brasília, assim como a do Brasil, sustenta-se sobre dois pilares: o da pluralidade e o do sofrimento, resultando daí uma identidade complexa, cuja delimitação se perde em nuanças múltiplas.

\section{REFERÊNCIAS}

ALMINO, João. Cidade Livre. Rio de Janeiro: Record, 2010.

BHABHA, Homi K. O local da cultura. Belo Horizonte: Editora UFMG, 1988.

HALL, Stuart. A identidade cultural na pós-modernidade. Rio de Janeiro: DP\&A, 2011.

\footnotetext{
${ }^{4}$ Conforme o Dicionário de nomes próprios, Moacyr tem origem na língua tupi e significa "dolorido, magoado", "o que vem da dor" ou "o que faz doer, o que magoa". Disponível em: <http://www.dicionariodenomesproprios.com.br/nomesmasculinos/m/2/>. Acesso em: 05 mai. 2016.
} 